\title{
GLASS-FIBRE REINFORCED COMPOSITES: THE EFFECT OF FIBRE LOADING AND ORIENTATION ON TENSILE AND IMPACT STRENGTH
}

\author{
0. Adekomaya ${ }^{1,{ }^{*}}$ and K. Adama ${ }^{2}$

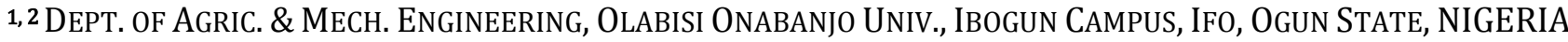 \\ E-mail addresses: ${ }^{1}$ oludaisiyetunde@gmail.com, ${ }^{2}$ leyekayadama@gmail.com
}

\begin{abstract}
The primary objective of this research work is to analyse the effect of fibre loading and orientation on the tensile and impact strength of the polymeric composite materials. Fibre reinforced composite materials have been reported to have attracted many applications in view of its low weight and superior strength when compared with the metal matrix composite. While researches have established the weight reduction of fibre reinforced polymer material, few works have reported the impact of orientation on the manufacturing of polymer composite. In this study, series of experimental works were done to demonstrate the manufacturing of glass-fibre reinforced epoxy resin with special attention on the influence of oriented reinforced composite material. The composites were manufactured using hand-lay technique with three different fibre loadings (10, 20, and $30 \mathrm{wt}$. \%) and at two different fibre orientations (30 and $\left.60^{\circ}\right)$. Key of the finding drawn from this research form the basis of discussion and, composite with $60^{\circ}$ fibre orientation showed better tensile strength when compared with the neat resin and other oriented $\left(G_{10} E_{30}\right)$ fibre reinforced composite. Similar observations were also noticed on the impact strength of these composites which signify the improved mechanical properties of oriented reinforced composite materials.
\end{abstract}

Keywords: glass fibre, orientation, fibre loading, impact strength, tensile strength.

\section{INTRODUCTION.}

Fibre reinforced composites have been widely explored in many literature in view of its lightness and improved modulus these materials have demonstrated in many engineering application. Application of polymer materials in many engineering application have enhanced the corrosion resistance and improved strength of many structures as witnessed in construction and building industries. Key of the factors that influence the properties of these composites are determined by fibre loading and orientation. According to Biswas, et al. [1], fibre loading enhances the strength of polymer composite and this property also determines the mechanical and corrosion wear behaviour of any reinforced composites. In other studies[2, 3], it was affirmed that the strength, stiffness, and toughness of fibre reinforced composite also improved as fibre content increases in any experimental composite. In line with other published work [4] on incremental fibre loading, fibre-reinforced polymer composites appear to have enjoyed good number of mechanical properties as tensile, impact and flexural tendencies of these properties increases as fibre contents increases. The experimental work conducted by Chowdhury, et al. [5] also corroborated the outcome of researches conducted by other papers[6-8] where tensile properties in these works improved as the fibre content is enhanced in the subsequent composite developed. Recent reports have revealed that enhancing the mechanical properties of fibre reinforced polymeric composites have made them suitable for some applications where metal matrix material have initially been used[9]. Part of the research finding reported by Cecen, et al. [10] categorically showed that apart from improved tensile properties of reinforced glass fibre epoxy resin, result of the differential scanning colorimetry (DSC) also revealed that glass fibre epoxy composite with $10 \%$ fibre content has higher thermal conductivity value when compared with glass fibre epoxy composite with $20 \%$ fibre content. Against this background, application of glass fibre epoxy resin seem to have been gaining momentum considering its thermal conductivity value and also its overall heat transfer coefficients when compared to natural fibre reinforced composite [11]. On the contrary, metals are generally reported $[2,12]$ to absorb energy in elasticplastic deformation, which may not be the case for fibrereinforced polymer (FRP) composite where in most cases exhibit a variety of fracture mechanisms including

\footnotetext{
* Corresponding author, tel: +234-803-441- 0652
} 
matrix deformation and fibre pull-out. Although, different contradictory results have been reported on the fibre reinforced polymeric composites, substantial part of these reports centred on treatments of glass fibre prior to reinforcement. According to Samal, et al. [12], the interfacial adhesion between the fibre and polymer matrices can be modified through various chemical treatments and heat treatment. Extensive studies on the application of heat treatment on glass fibre to improve the compatibility of the fibre with the phase matrix have been widely reported in the literature[13, 14]. In the light of the above, glass fibre has recently been adjudged as one of the best insulating materials for thermal energy saving as manufacturers continue to explore new materials with lower thermal conductivity value. Cecen and co-workers also investigated thermal advantages of glass fibre as a reinforcement for energy conservation in their experimental work where differential scanning calorimeter (DSC) was adapted to indicate the thermal conductivity measurements of composite specimens in the direction of the fibre loading over the temperature range of 45-2358C. The results showed that thermal conductivity value decreases as the fibre content in the composite increases. Although there exist in the literature a huge knowledge base for the application of glass fibre in various engineering practises, only restricted information is available on the application of oriented reinforced glass fibre as per its improved tensile properties. In furtherance to this properties of glass fibre, some papers $[15,16]$ have recently faulted earlier attempt to categorise glass fibre as non-recyclable. Specifically, according to a study presented by Felix Antonio, et al. [17] in which recycled glass fibres from fibreglass polyester waste composite was processed for the production of glass-ceramic materials and the conclusion drawn from the research indicated that the emerging product from sintered powder glass samples $(<63 \mu \mathrm{m})$ can still be useful in the formation of wollastonite-plagioclase glass-ceramic materials for architectural applications.

\section{PREPARATION OF COMPOSITES.}

In this work, fiber-reinforced matrix composites were manufactured using hand-lay-up technique in line with previous studies $[18,19]$ and the concept of fiber orientation in the composite was equally adopted in this research in order to analyse the effect of orientation of glass fiber on the mechanical properties of the composites particularly on tensile and impact energy. Newly manufactured ampreg-21 epoxy resin, which belongs to the larger family of epoxides was employed as the matrix material and woven E glass fiber was used as a reinforcing fiber. The ampreg 21 epoxy resin and the corresponding Ampreg 21 hardener are mixed in a ratio of 100:33 by weight as prescribed in the manufacturer data sheet and all the composites were prepared at room temperature as reported elsewhere [20, 21]. Glass fiber mat was cut to shape of the mould and pre-heated in an oven at $1000^{\circ} \mathrm{C}$ for 30 minutes in order to freeze any moisture interaction with the fiber. The resin-hardener compound was applied to the pre-weighed glass fiber in the mould cavity before curing. The experimental procedure is illustrated in Figure 1.

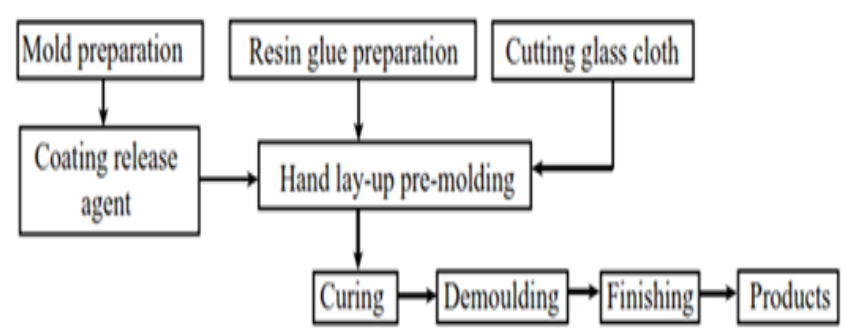

Figure 1: Experimental procedure of composite sheet formation

This experimental work developed five (5) different composite sheets at various degrees of fiber enhancement and the manufacturing parameters were based on different $\%$ fiber loadings and orientations. The composite sheets were developed with three (3) different fiber loadings $(10,20$ and 30 wt. \%), which were denoted as: $\mathrm{G}_{10} \mathrm{E}, \mathrm{G}_{20} \mathrm{E}$ and $\mathrm{G}_{30} \mathrm{E}$, respectively all at $0^{\circ}$ orientation and the glass fibers were arranged in two (2) different fiber orientations with respective to the reinforcing base fiber $\left(30^{\circ}\right.$ and $\left.60^{\circ}\right)$ which were also represented by $\mathrm{G}_{20} \mathrm{E}_{30}$ and $\mathrm{G}_{20} \mathrm{E}_{60}$. The weight percent of fiber at $30^{\circ}$ and $60^{\circ}$ orientations in these composites, are 10 and $20 \%$ weights, respectively.

\subsection{Impact Analysis of Composite Specimens}

In line with other published works, the test specimens for impact test were prepared according to ASTM D $256 \mathrm{M}$ and all the specimens were notched with a root radius $0.25 \mathrm{~mm}$ at $2 \mathrm{~mm}$ depth and the composite specimen were $70 \mathrm{~mm}$ long, approximately $2 \mathrm{~mm}$ thick and $10 \mathrm{~mm}$ wide[22, 23]. The impact speed was set at 3.6 $\mathrm{m} / \mathrm{s}$, employing a hammer drop energy of $7.7 \mathrm{~J}$ and span in-between the supports was stationed at $40 \mathrm{~mm}$. Three specimens were tested from each panel and the average were reported and evaluated. The Charpy impact apparatus consists of a sharp file or axe at an angle of $45^{\circ}$, swinging at a notched position of the specimen, which subsequently fractured at the notched edge of the samples. According to Swetha and Kumar [24] and Manfredi, et al. [25], it is important for notched specimens to have equal geometry and dimensions as these parameters ultimately affect the results of the impact test. These authors also reported that the sample 
size are to be properly carved according to ASTM standard since these dimensions determine whether a specimen is in plain strain. This gap can greatly influence conclusions made.

\subsection{Determination of Tensile Properties of Composite Specimens.}

Tensile properties of the composite panels were evaluated according to ASTM D638, using dog-bone shaped samples (Figure 2). The dog-bone specimen with dimensions: $75 \mathrm{~mm}$ of length $\mathrm{X} 12 \mathrm{~mm}$ of width $\mathrm{X} 2 \mathrm{~mm}$ of thickness, as shown below were carved out from the reinforced polymeric composites.

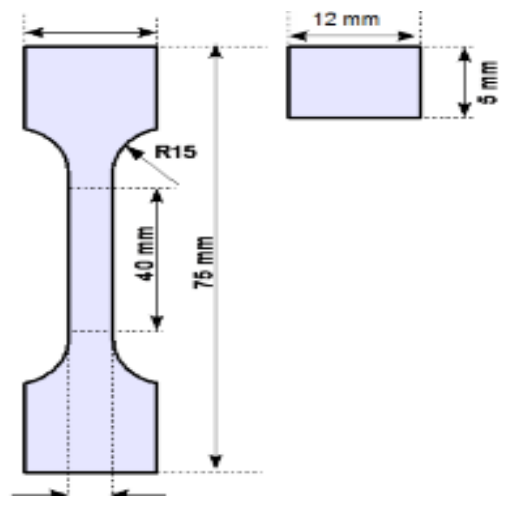

Figure 2:Dog-bone specimen of the tensile test.

Some authors [26, 27] have devised a means of minimising the effect of tension grip on the test specimen, in which they argued in their studies, may cause large stress concentration in the specimen. The dog-bone specimen were subjected to tensile loads on a computer monitored INSTRON Universal Testing Machine and the tests were conducted at a constant crosshead speed of $5.0 \mathrm{~mm} /$ minusing a load cell of 10 kN. Five sample specimens were tested for each composite panel and only the arithmetic mean with a negligible standard deviation was selected for statistical and result analysis. In this work, the tensile strength of the composite panel is defined as the ultimate strength at which the total fracture of the dog-bone specimen occurs and the corresponding load is also defined as the critical load or the maximum load a composite panel can withstand. The tensile tests on all specimens were conducted at room temperature as reported in similar works $[7,28]$

\section{RESULT AND DISCUSSION}

Critical discussion on the performance of composite specimens were done using composite designates to define each of the specimen to avoid repetition. Table 1provides the composite designates and their corresponding compositions.
Table 1: Composite designate and its respective compositions

\begin{tabular}{|c|c|}
\hline $\begin{array}{l}\text { Composite } \\
\text { Designation }\end{array}$ & $\begin{array}{l}\text { Compositions and fibre orientations } \\
\text { in the composites }\end{array}$ \\
\hline $\mathrm{G}_{10} \mathrm{E}$ & $\begin{array}{l}10 w t \% \text { fiber enhancement at } 0^{\circ} \\
\text { orientation }\end{array}$ \\
\hline $\mathrm{G}_{20} \mathrm{E}$ & $\begin{array}{l}20 \mathrm{wt} \% \text { fiber enhancement at } 0^{\circ} \\
\text { orientation }\end{array}$ \\
\hline $\mathrm{G}_{30} \mathrm{E}$ & $\begin{array}{l}30 \mathrm{wt} \% \text { fiber enhancement at } 0^{\circ} \\
\text { orientation }\end{array}$ \\
\hline $\mathrm{G}_{10} \mathrm{E}_{30}$ & $\begin{array}{l}10 \mathrm{wt} \% \text { fiber enhancement at } 30^{\circ} \\
\text { orientation }\end{array}$ \\
\hline $\mathrm{G}_{20} \mathrm{E}_{60}$ & $\begin{array}{l}20 \mathrm{wt} \% \text { fiber enhancement at } 60^{\circ} \\
\text { orientation }\end{array}$ \\
\hline
\end{tabular}

The detailed analysis of the Charpy impact test of all the composite specimens are presented in Figure 3, where each value represents the mean of 3 tests/specimen and the standard deviation was equally estimated and this is denoted as the error bar, as illustrated in the plot. The Charpy impact test gives a precise record of the hammer impact event on the specimen. The measured impact energies of the fiber reinforced composite are compared with the value of neat epoxy (E), recorded under the same room temperature condition. It can be seen from Figure 3 that the impact strength increases with respect to fiber loading, irrespective of the fiber orientation. Considering the value of the impact energy of the neat epoxy resin, it can be inferred that there is about $116 \%$ increase in the impact energy of composite specimen $\mathrm{G}_{30} \mathrm{E}$ when compared with the neat epoxy resin. It can also be observed that the impact strength increases with respect to fiber contents until it reaches a maximum strength of $7.57 \mathrm{~J} / \mathrm{m}^{2}$ for the $0^{\circ}$ orientated specimen. In case of oriented fiber, it can be noticed that that there is about $8.89 \%$ increment in $\mathrm{G}_{20} \mathrm{E}_{60}$ when compared with $\mathrm{G}_{10} \mathrm{E}_{30}$. This trend clearly shows that the influence of reinforcement is reasonably high in determining the impact energy of a composite material. This conclusion is similar to an argument proposed by Chandramohan and Bharanichandar [29] in which the authors affirmed that the impact strength of unidirectional hemp/polyester composite specimens displayed a linear increase scenario with increasing fiber content. It is also important to note that there is $\sim 19.2 \%$ improvement in the impact strength when fiber content was increased from 10 to $30 \%$ at $0^{\circ}$ orientation. In a related manner, the impact strength of the specimen $\mathrm{G}_{10} \mathrm{E}$ increased by $\sim 4.6 \%$ when compared with specimen $\mathrm{G}_{10} \mathrm{E}_{30}$, while specimen $\mathrm{G}_{20} \mathrm{E}$ equally increased in impact strength by $\sim 8.77 \%$ when compared with specimen $\mathrm{G}_{20} \mathrm{E}_{60}$.

In a tensile experiment, the applied load is believed to be transferred from the matrix to the reinforcing fiber at the interface of the reinforced composites. A plot of the tensile stress versus strain of a typical reinforced epoxy resin is shown in the Figure 4. 


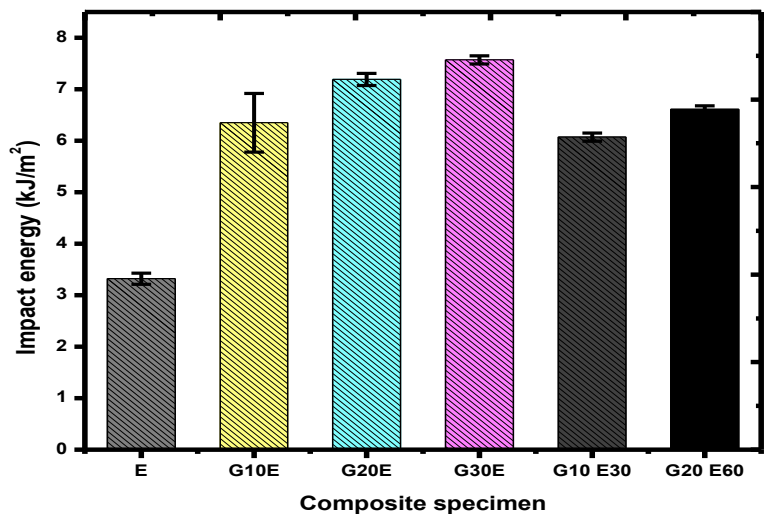

Figure 3: Effect of fiber content on impact strength of reinforced composites. Error bar represents standard deviation

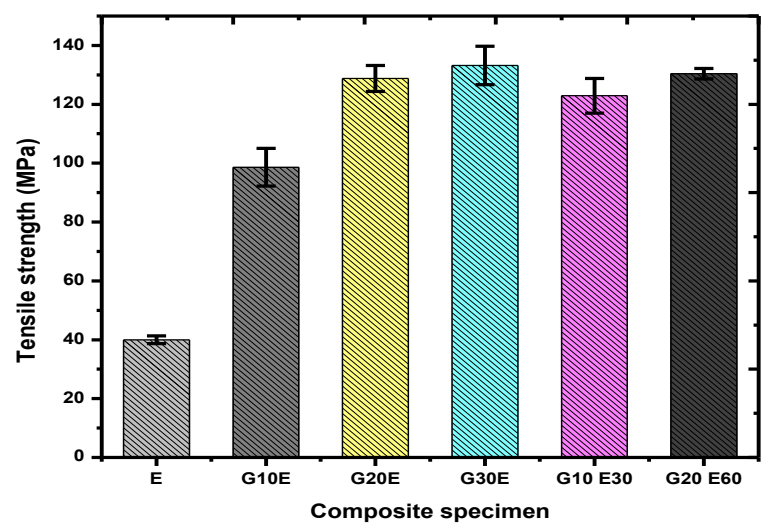

Figure 5: Effect of fiber content on tensile strength of composite specimens. Error bar represents standard deviation

From this graph, it can be deduced that the initial linear portion of the graph shows the elastic behaviour of the composite specimen, which is consistent as observed in the sharp increment from $\mathrm{G}_{10} \mathrm{E}$ to $\mathrm{G}_{30} \mathrm{E}$. The deviation from this linearity as noticed from decline in $\mathrm{G}_{10} \mathrm{E}_{30}$ and $\mathrm{G}_{20} \mathrm{E}_{60}$ is believed to have occasioned by initial matrix cracking and the end of the curve represents the ultimate stress which may have been as result fiber pull-out or agglomeration within the matrix. The implication of the glass fibers as a reinforcement on the tensile ability of an epoxy cross linked network was further studied and the results analysed, as shown in Figure 5.

From Figures 5 and 6, it can be observed that there is a significant improvement in the tensile strength and modulus of specimens $\mathrm{G}_{10} \mathrm{E}, \mathrm{G}_{20} \mathrm{E}$ and $\mathrm{G}_{30} \mathrm{E}$ in comparison with the neat epoxy resin (E). Statistically, there is $\sim 145 \%$ improvement in the tensile strength of $\mathrm{G}_{10} \mathrm{E}$ and $\sim 65 \%$ increment in the Young's modulus of the same specimen when compared with the tensile strength and the Young's modulus of the neat epoxy (E) resin. It is also important to note that the tensile strength and modulus for oriented fiber composite specimen equally improved

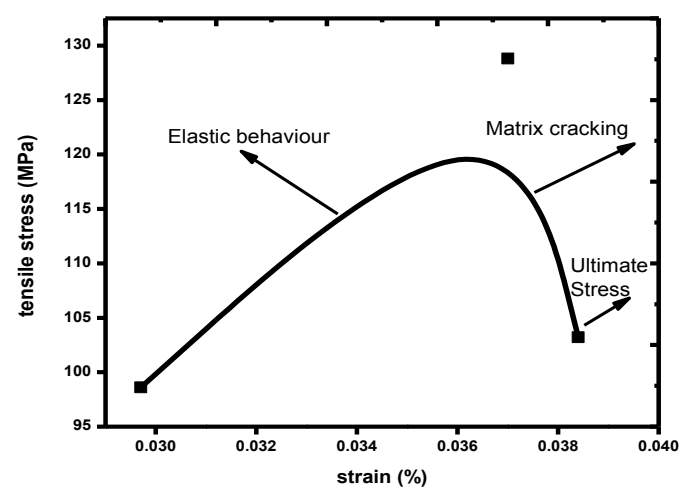

Figure 4: Stress-strain analysis of glass fiber reinforced epoxy resin

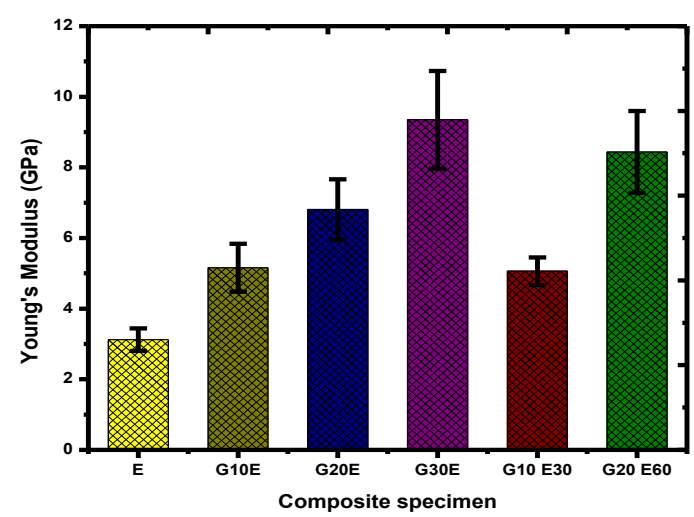

Figure 6: Impact of fiber content on young modulus of reinforced composites. Error bar represents standard deviation

with respect to fiber loading. For instance, there is $\sim 6.55 \%$ improvement in the tensile strength of $\mathrm{G}_{20} \mathrm{E}_{60}$ when compared with the $\mathrm{G}_{10} \mathrm{E}_{30}$ specimen. In the same manner, the tensile modulus of $\mathrm{G}_{20} \mathrm{E}_{60}$ equally experienced a $66.8 \%$ leap when compared with the $\mathrm{G}_{10} \mathrm{E}_{30}$ specimen. The increase in the tensile strength can be attributed to the stiffness imposed in the composite by the reinforced glass fiber as well as the better interfacial distribution of glass fibers in the resin. Composite specimens that recorded decreases in their tensile strength are believed to have high-resinnormalised void content. According toBiswas, et al. [1], the development of void in the composite can adversely affect the tensile strength and modulus of composite. Some authors have also adduced the reason for the decline in strength to the poor fiber-to-fiber interaction at high fiber loadings, which may not have effectively contributed to the stress transfer in the specimen.

The tensile properties of epoxy resin and short carbon fiber composites were studied by Dong, et al. [22] and Kanny and Mohan [30]. These authors equally corroborated previous observations noticed in this 
study, by submitting that poor fiber and matrix adhesion can aggravate a decline inthe tensile strength and modulus of the composites. Several other authors have anchored the improved tensile properties of a typical composite material on the fiber-matrix adhesion, which also enhances a better stress transfer efficiency of a composite material. The interface between the fiber and the matrix also determines the strength and ultimately the load subjected to a composite. Other properties that may enhance the tensile properties of a composite as reported in similar worksinclude modulus of reinforced fibers (on itself), chemical properties of the matrix and the performance of the bonding strength between matrix and the fiber. As each composite panel is subjected to an applied load, the reinforced fibers try to position themselves in a direction perpendicular to the applied load. The re-alignment of the glass fibers is reported to make the composite more resilient in sustaining the load, thereby increasing the toughness of the materials and therefore the material becomes more competent to withstand deformation or bear the applied load. It is practically advised that tensile strength tends to decline in many experimental works due to the poor interfacial adhesion that can initiate micro-crack along different directions in the composite and also lead to the nonuniform stress transfer within the fibers, due to the agglomeration within the matrix. The brittle nature of cured epoxy resin and the glass fiber appear to be major challenges in the application of epoxy resin and the glass fiber, which often occurs during the peak stress. A total failure of the fiber reinforced composite carrying capacity can occur, resulting in the sudden stress decline to zero. In view of the fact that the elastic moduli of the reinforced glass fiber composites were often higher than the unreinforced neat matrix, means that the elongations-to-failure of the reinforced composites were considerably higher when compared to the failure of a neat matrix, which can impose considerable strains and high stresses.

\section{CONCLUSIONS.}

In this study, it can be inferred that the experimental investigation of oriented reinforced composite material have established the following improved mechanical and physical properties of glass fibre reinforced epoxy resin and the following conclusion is further established.

* This research study has proved that glass fibrereinforced epoxy composites could be manufactured by hand lay-up technique at different degree of fibre loading and fibre orientation.

* This experimental study further showed the impact energy is a function of fibre enhancement. Composite specimen $\left(\mathrm{G}_{30} \mathrm{E}\right)$ indicated an improved strength when compared with other composite material irrespective offibre loading or fibre orientation.

* It is also observed that that the tensile strength and modulus of $\mathrm{G}_{30} \mathrm{E}$ shows a significant improvement when compared with the neat resin (E) and the other composite specimen. This may not be unconnected with the toughening strength of the glass fibre.

\section{ACKNOWLEDGEMENT}

The lead author would like to thank Tshwane University of Technology, Pretoria, South Africa for the platform to conduct this research. The authors would also appreciate some of the literatures that have provided comprehensive background of glass fibre.

\section{REFERENCES.}

[1] S. Biswas, B. Deo, A. Patnaik, and A. Satapathy, "Effect of fiber loading and orientation on mechanical and erosion wear behaviors of glassepoxy composites," Polymer Composites, vol. 32, pp. 665-674, 2011.

[2] N. A. Rahman, A. Hassan, R. Yahya, and R. LafiaAraga, "Impact properties of glassfiber/polypropylene composites: The influence of fiber loading, specimen geometry and test temperature," Fibers and Polymers, vol. 14, pp. 1877-1885, 2013.

[3] A. Zheng, H. Wang, X. Zhu, and S. Masuda, "Studies on the interface of glass fiber-reinforced polypropylene composite," Composite Interfaces, vol. 9, pp. 319-333, 2002.

[4] F. Ashiedu and E. Akpan, "Effects of Mixed Alkaline Earth Oxides in Potash Silicate Glass," Nigerian Journal of Technology, vol. 34, pp. 731-736, 2015.

[5] F. Chowdhury, M. Hosur, and S. Jeelani, "Investigations on the thermal and flexural properties of plain weave carbon/epoxy-nanoclay composites by hand-layup technique," Journal of materials science, vol. 42, pp. 2690-2700, 2007.

[6] E. Pérez-Pacheco, J. Cauich-Cupul, A. ValadezGonzález, and P. Herrera-Franco, "Effect of moisture absorption on the mechanical behavior of carbon fiber/epoxy matrix composites," Journal of materials science, vol. 48, pp. 1873-1882, 2013.

[7] K. Zhang, Y. Gu, M. li, and Z. Zhang, "Effect of rapid curing process on the properties of carbon fiber/epoxy composite fabricated using vacuum assisted resin infusion molding," Materials \& Design, vol. 54, pp. 624-631,2014.

[8] Z. Zhao, X. Chen, and X. Wang, "Deformation behavior of woven glass/epoxy composite substrate under thermo-mechanical loading," Materials \& Design, vol. 82, pp. 130-135, 2015. 
[9] O. Adekomaya, T. Jamiru, R. Sadiku, and Z. Huan, "Minimizing energy consumption in refrigerated vehicles through alternative external wall," Renewable and Sustainable Energy Reviews, vol. 67, pp. 89-93, 2017.

[10] V. Cecen, I. H. Tavman, M. Kok, and Y. Aydogdu, "Epoxy-and polyester-based composites reinforced with glass, carbon and aramid fabrics: Measurement of heat capacity and thermal conductivity of composites by differential scanning calorimetry," Polymer Composites, vol. 30, pp. 1299-1311, 2009.

[11] O. Adekomaya, T. Jamiru, R. Sadiku, and Z. Huan, "Negative impact from the application of natural fibers," Journal of Cleaner Production, vol. 143, pp. 843-846, 2017.

[12] S. K. Samal, S. Mohanty, and S. K. Nayak, "Banana/glass fiber-reinforced polypropylene hybrid composites: Fabrication and performance evaluation," Polymer-Plastics Technology and Engineering, vol. 48, pp. 397-414, 2009.

[13] L. Yang and J. Thomason, "Interface strength in glass fibre-polypropylene measured using the fibre pullout and microbond methods," Composites Part A: Applied Science and Manufacturing, vol. 41, pp. 1077-1083, 2010.

[14] D. W. Lee, S. Ma, and K. Y. Lee, "Electrical and mechanical properties of carbon/glass hybridized long fiber reinforced polypropylene composites," Macromolecular Research, vol. 21, pp. 767-774, 2013.

[15] P. Asokan, M. Osmani, and A. D. Price, "Assessing the recycling potential of glass fibre reinforced plastic waste in concrete and cement composites," Journal of Cleaner Production, vol. 17, pp. 821-829, 2009.

[16] X.-D. Liu, D.-K. Sheng, X.-M. Gao, T.-B. Li, and Y.-M. Yang, "UV-assisted surface modification of PET fiber for adhesion improvement," Applied Surface Science, vol. 264, pp. 61-69, 2013.

[17] L. Felix Antonio, M. Maria Isabel, G.-D. Irene, R. Olga, A. Francisco Jose, and R. Maximina, "Recycling of glass fibers from fiberglass polyester waste composite for the manufacture of glass-ceramic materials," Journal of Environmental Protection, vol. 2012.

[18] H. Joshi, A. Tiwari, and R. Goyal, "Improvement in thermal, mechanical and water resistance properties of epoxy/glass particulate composites," International Journal of Plastics Technology, vol. 14, pp. 167-178, 2010.

[19] M. Jawaid, O. Y. Alothman, N. Saba, M. Paridah, and H. Abdul Khalil, "Effect of fibers treatment on dynamic mechanical and thermal properties of epoxy hybrid composites," Polymer Composites, 2014.

[20] G. Oliveux, L. O. Dandy, and G. A. Leeke, "Current status of recycling of fibre reinforced polymers: Review of technologies, reuse and resulting properties," Progress in Materials Science, vol. 72, pp. 61-99, 2015.

[21] F. M. AL-Oqla, S. Sapuan, M. Ishak, and A. Nuraini, "A Model for Evaluating and Determining the Most Appropriate Polymer Matrix Type for Natural Fiber Composites," International Journal of Polymer Analysis and Characterization, 2015.

[22] W. Dong, H.-C. Liu, S.-J. Park, and F.-L. Jin, "Fracture toughness improvement of epoxy resins with short carbon fibers," Journal of Industrial and Engineering Chemistry, vol. 20, pp. 1220-1222, 2014.

[23] M. Shokrieh, M. Torabizadeh, and A. Fereidoonc, "A new method for evaluation of mechanical properties of glass/epoxy composites at low temperatures," Strength of Materials, vol. 44, pp. 87-99, 2012.

[24] C. Swetha and R. Kumar, "Quasi-static uni-axial compression behaviour of hollow glass microspheres/epoxy based syntactic foams," Materials \& Design, vol. 32, pp. 4152-4163, 2011.

[25] L. B. Manfredi, H. De Santis, and A. Vázquez, "Influence of the addition of montmorillonite to the matrix of unidirectional glass fibre/epoxy composites on their mechanical and water absorption properties," Composites Part A: Applied Science and Manufacturing, vol. 39, pp. 1726-1731, 2008.

[26] I. Dagwa, K. Adama, A. Gadu, and N. Alu, "Tensile and Hardness Property Evaluation of Kaolin-Sisal Fibre-Epoxy Composite," Nigerian Journal of Technology, vol. 34, pp. 750-760, 2015.

[27] E. Nassar, "Study on mechanical properties of epoxy polymer reinforced with NanoSiC particles," Nanoscience and Nanoengineering, vol. 1, pp. 89-93, 2013.

[28] J. L. Thomason and L. Yang, "Temperature dependence of the interfacial shear strength in glass-fibre epoxy composites," Composites Science and Technology, vol. 96, pp. 7-12, 2014.

[29] D. Chandramohan and J. Bharanichandar, "Natural fiber reinforced polymer composites for automobile accessories," American Journal of Environmental Sciences, vol. 9, p. 494, 2013.

[30] K. Kanny and T. P. Mohan, "Resin infusion analysis of nanoclay filled glass fiber laminates," Composites Part B: Engineering, vol. 58, pp. 328-334, 2014. 